\title{
Detection and Monitoring of Methotrexate-associated Lung Injury Using Serum Markers KL-6 and SP-D in Rheumatoid Arthritis
}

\author{
Masayuki Miyata, Fumitaka Sakuma, Etsuko Fukaya*, Hiroko Kobayashi*, Takeshi Rai*, \\ Hironobu SaITo*, Reiji KaSUKaWA** and Shuzo SUZUKI*
}

\begin{abstract}
The applicability of monitoring concentrations of serum KL-6 and serum surfactant protein-D (SP-D) in the detection of methotrexate-associated lung injury (MTX pneumonitis) in patients with rheumatoid arthritis (RA) was investigated. The concentrations of these markers, sequentially measured in two patients with RA complicated with MTX pneumonitis, were increased in accordance with the severity of MTX pneumonitis. Conversely, the concentrations of these markers were decreased with the improvement of MTX pneumonitis, suggesting that the monitoring of these markers could be applicable not only for detecting the onset of MTX pneumonitis, but also for detecting the therapeutic response of MTX pneumonitis.

(Internal Medicine 41: 467-473, 2002)
\end{abstract}

Key words: MTX, pneumonitis, pulmonary tuberculosis, pulmonary adenocarcinoma, type II pneumocyte

\section{Introduction}

A weekly pulse of low-dose methotrexate (MTX) is an effective and the most popular therapy for rheumatoid arthritis (RA). One of the most serious complications of MTX therapy is MTX-associated lung injury (MTX pneumonitis) (1). Golden et al suggested that preexisting interstitial pneumonia (IP) characterized by radiographic interstitial infiltrates may predispose patients with RA to developing MTX pneumonitis (2). Moreover, Alarcon et al listed the risk factors for MTX pneumonitis such as old age ( $\geq 60$ years old), diabetes mellitus, previous use of disease-modifying antirheumatic drugs, and hypoalbuminemia $(<3.9 \mathrm{~g} / \mathrm{dl})$ in addition to preexisting IP in a multicenter, case-control study (3). Previous reports and our experience in- dicate that MTX pneumonitis is emerging as one of the most unpredictable complications; it is not dose-dependent, and it is a type of hypersensitivity pneumonitis (4).

MTX has tremendous therapeutic value in RA patients even with preexisting IP; therefore, preexisting IP should be a relative, not an absolute contraindication in prescribing MTX to RA patients. Because $40 \%$ of RA patients have some pulmonary dysfunction $(5,6)$, the problem of distinguishing MTX pneumonitis from preexisting IP exists. In this regard, a marker that can not only detect the onset of MTX pneumonitis but can also differentiate MTX pneumonitis from preexisting IP is highly desired.

KL-6 and SP-D are recently developed serum markers useful for detecting hypersensitivity pneumonitis, idiopathic IP and IP associated with collagen vascular diseases (7-10). However, the usefulness of these serum markers for detecting MTX pneumonitis has not yet been established. We hypothesized that KL-6 and SP-D can be valuable for use as markers in detecting the onset of MTX pneumonitis as well as for differentiating MTX pneumonitis from preexisting IP. In this study, we demonstrated that these serum markers show promise in detecting the onset of MTX pneumonitis, in differentiating MTX pneumonitis from preexisting IP, and in monitoring the therapeutic outcome of MTX pneumonitis.

\section{Materials and Methods}

\section{Measurement of serum KL-6 concentration}

The concentration of serum KL-6 antigen was measured using a sandwich-type enzyme-linked immunosorbent assay (ELISA) (11) kit (Eitest KL-6, Eisai Co., Tokyo, Sanko Pharmaceutical Co., Tokyo).

\section{Measurement of serum SP-D concentrations}

The concentration of serum SP-D antigen was measured using a sandwich-type ELISA (12) kit (SP-D kit, Yamasa Co.,

From Department of Internal Medicine, Fukushima Red Cross Hospital, Fukushima, *Department of Internal Medicine II, Fukushima Medical University School of Medicine, Fukushima and **Ohta General Hospital Foundation Institution for Rheumatic Diseases, Fukushima

Received for publication August 6, 2001; Accepted for publication January 21, 2002

Reprint requests should be addressed to Dr. Masayuki Miyata, Department of Internal Medicine, Fukushima Red Cross Hospital, 1-43 Irie-cho, Fukushima 960-8530 
Tokyo).

\section{Patients}

Patient 1

A 66-year-old man suffering from RA since 1995 was undergoing treatment with gold salt injection and prednisolone, followed by a $2.5 \mathrm{mg} /$ day to $5 \mathrm{mg} /$ day weekly pulse of MTX initiated in March 1997, as shown in Fig. 1. The representative laboratory data when the weekly pulse of MTX was initiated were as follows; erythrocyte sedimentation rate, $96 \mathrm{~mm} / \mathrm{h}$ (nor$\mathrm{mal}:<20$ ); CRP, $4.5 \mathrm{mg} / \mathrm{dl}$ (normal: $<0.3$ ); and serum albumin level, $2.8 \mathrm{~g} / \mathrm{dl}$ (normal: 4.0-5.3). He was first hospitalized in the Department of Internal Medicine II of Fukushima Medical University Hospital in June 1998 because of pulmonary tuberculosis, and MTX administration was stopped. A roentgenogram and CT scan revealed lesions of pulmonary tuberculosis and a preexisting IP, as shown in Fig. 2A and B, respectively. The concentrations of serum KL-6 and SP-D on admission were
$576 \mathrm{U} / \mathrm{ml}$ (normal: <500) and $53.9 \mathrm{ng} / \mathrm{ml}$ (normal: <110), respectively. He was discharged from the hospital in October 1998, showing improvement of the tuberculosis.

He complained of severe polyarthralgia with aggravation of RA afterwards, therefore, we readministered $5.0 \mathrm{mg} /$ week of MTX in August 1999 at his request since he was completely cured of tuberculosis. He was hospitalized again in January 2000 to investigate the cause of fever, dry cough, shortness of breath and general malaise which started one week prior to the second admission.

The roentgenogram and CT scan revealed pneumonitis, as shown in Fig. 2C and D. The cumulative amount of MTX he received was $380 \mathrm{mg}$. The roentgenogram of the lung taken in December 1999 is shown in Fig. 2E. Retrospectively, the interstitial pneumonitis had already been apparent as shown in this figure. The representative laboratory data on admission were as follows: serum KL-6, 1,100 U/ml; serum SP-D, $298 \mathrm{ng} / \mathrm{ml}$; CRP, 18.2 mg/dl; LDH, 639 IU/l (normal: 250-410); BUN,

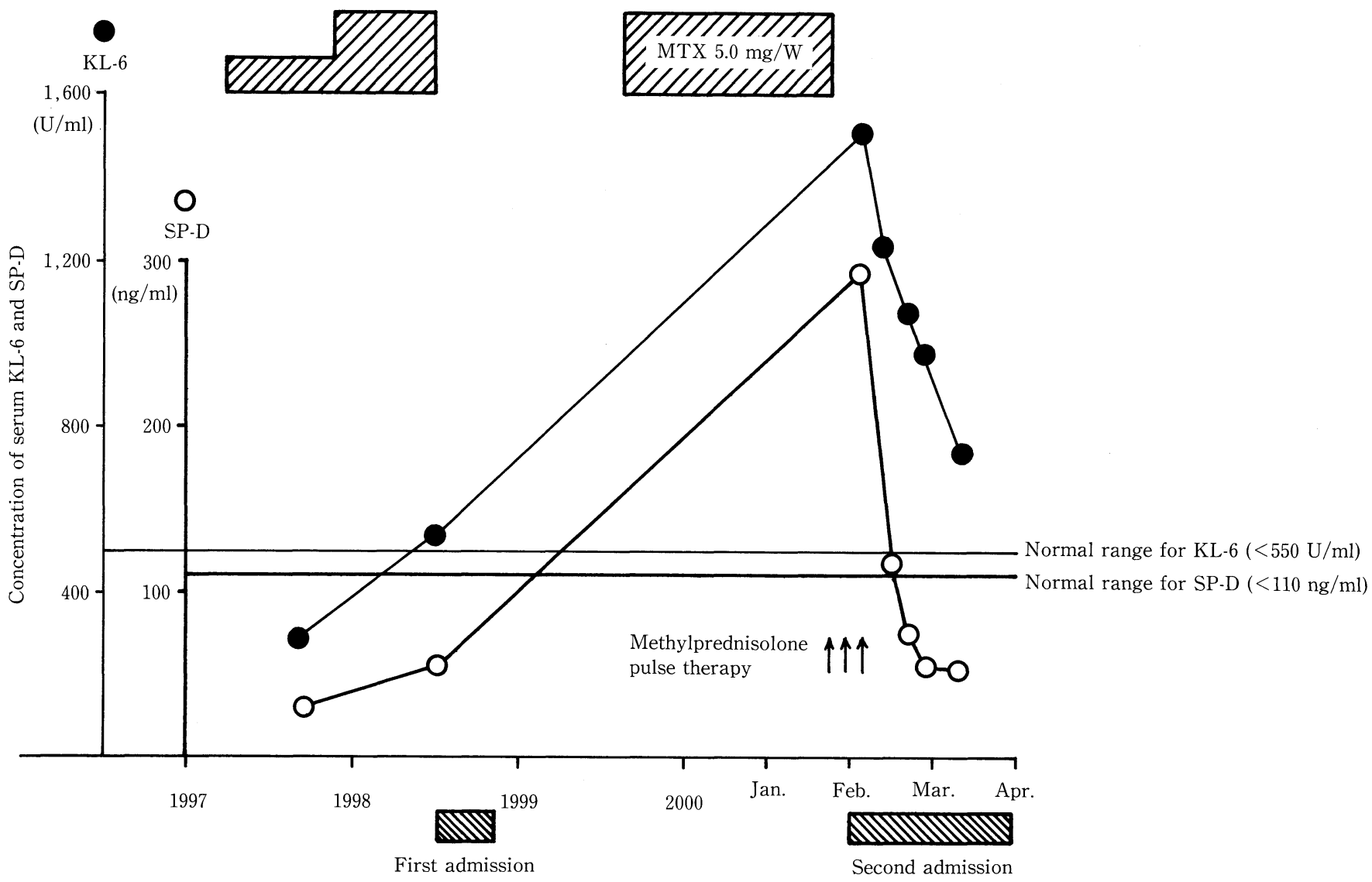

Figure 1. Clinical course of Patient 1. This patient suffered from RA since 1995 and was undergoing treatment with a 2.5 to 5 mg/day weekly pulse of MTX. He was hospitalized in 1998 because of lung tuberculosis, and MTX administration was stopped (first admission). The concentrations of serum KL-6 and SP-D on admission were 576 U/ml (normal: <550) and 53.9 ng/ml (normal: <110), respectively. MTX was readministered in 1999 and he was hospitalized again in 2000 because of MTX pneumonitis (second admission). The concentrations of serum KL-6 and SP-D increased to 1,100 U/ml and $298 \mathrm{ng} / \mathrm{ml}$, respectively. Methylprednisolone pulse therapy $(1,000 \mathrm{mg} /$ day $\times 3$ days $)$ was initiated and the concentrations of serum KL-6 and SP-D decreased to $687 \mathrm{U} / \mathrm{ml}$ and $82.2 \mathrm{ng} / \mathrm{ml}$, respectively. 

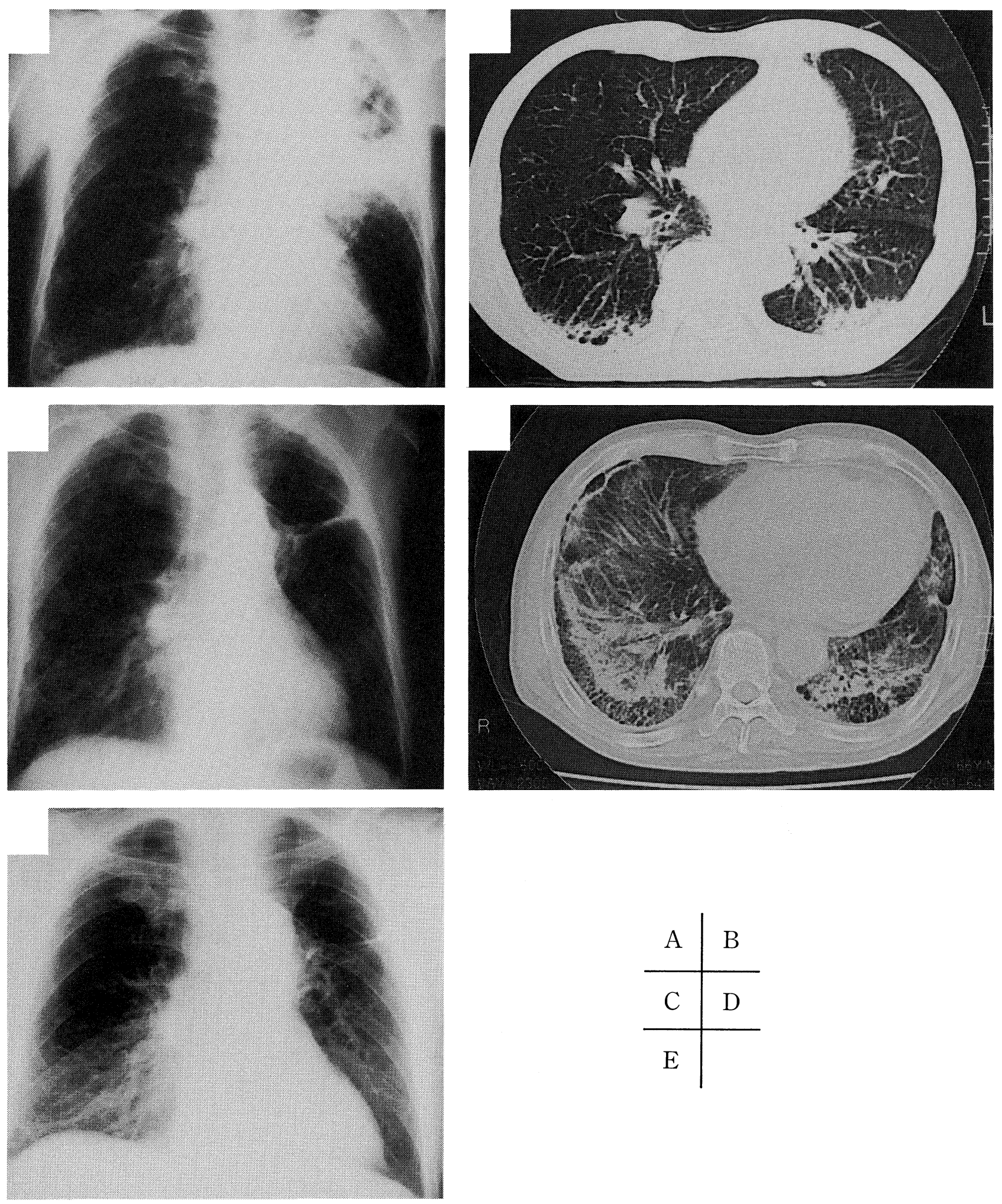

Figure 2. The roentgenograms and CT scans of Patient 1. The roentgenogram and CT scan taken in 1998 reveal a pulmonary tuberculosis lesion in the left upper lung field and a preexisting interstitial pneumonia in the lower, posterior field of both lungs as shown in (A) and (B), respectively. The roentgenogram and CT scan taken in 2,000 reveal widespread interstitial pneumonia in both lung fields as shown in (C) and (D). The roentgenogram of the lung taken in December 1999 discloses that the interstitial pneumonia is already present as shown in $(\mathrm{E})$. 
$15.1 \mathrm{mg} / \mathrm{ml}$ (normal: $9-20)$; creatinine, $1.3 \mathrm{mg} / \mathrm{dl}$ (normal: $0.5-$ 1.0); $\mathrm{PaO}_{2}, 41.4 \mathrm{mmHg}$; and $\mathrm{PaCO}_{2}, 27.3 \mathrm{mmHg}$.

The patient was diagnosed as having MTX pneumonitis under the revised diagnostic criteria for adverse pulmonary events associated with MTX treatment of RA (13), and methylprednisolone pulse therapy $(1,000 \mathrm{mg} / \mathrm{day} \times 3$ days $)$ was initiated. The concentrations of serum KL-6 and SP-D decreased to $687 \mathrm{U} / \mathrm{ml}$ and $82.2 \mathrm{ng} / \mathrm{ml}$, respectively after one month along with an improvement of dyspnea and roentgenographic findings. However, the pneumonitis shadow was not completely resolved as determined by roentgenography at the end of March (data not shown).

\section{Patient 2}

A 64-year-old woman suffering from RA since 1988 was undergoing treatment with gold salt followed by a $5 \mathrm{mg} / \mathrm{day}$ weekly pulse of MTX since March, 1999, as shown in Fig. 3.
She was on a special diet because of diabetes mellitus and chronic renal failure. The representative laboratory data when weekly pulse of MTX was initiated were as follows: erythrocyte sedimentation rate, $105 \mathrm{~mm} / \mathrm{h} ; \mathrm{CRP}, 4.7 \mathrm{mg} / \mathrm{dl}$; serum albumin level, $3.6 \mathrm{~g} / \mathrm{dl}$; fasting blood sugar, $195 \mathrm{mg} / \mathrm{dl}$ (normal<110); HB-A, $8.3 \%$ (4.3-5.8); BUN, $35 \mathrm{mg} / \mathrm{ml}$ (normal: 9-20); and creatinine, $2.1 \mathrm{mg} / \mathrm{dl}(0.5-1.0)$. She was first hospitalized in May 1999 in the Department of Internal Medicine II of Fukushima Medical University Hospital for the investigation of an abnormal lesion in the right middle lung field, as shown in Fig. 4A. Roentgenogram, CT scan and cytology of the tumorous lesion revealed that the lesion was most likely a pulmonary adenocarcinoma; therefore, we recommended that she undergo an operation for this pulmonary tumor, but she refused because she was also suffering from chronic renal failure since 1996, possibly due to the preexisting diabetes mellitus or previous gold salt therapy.

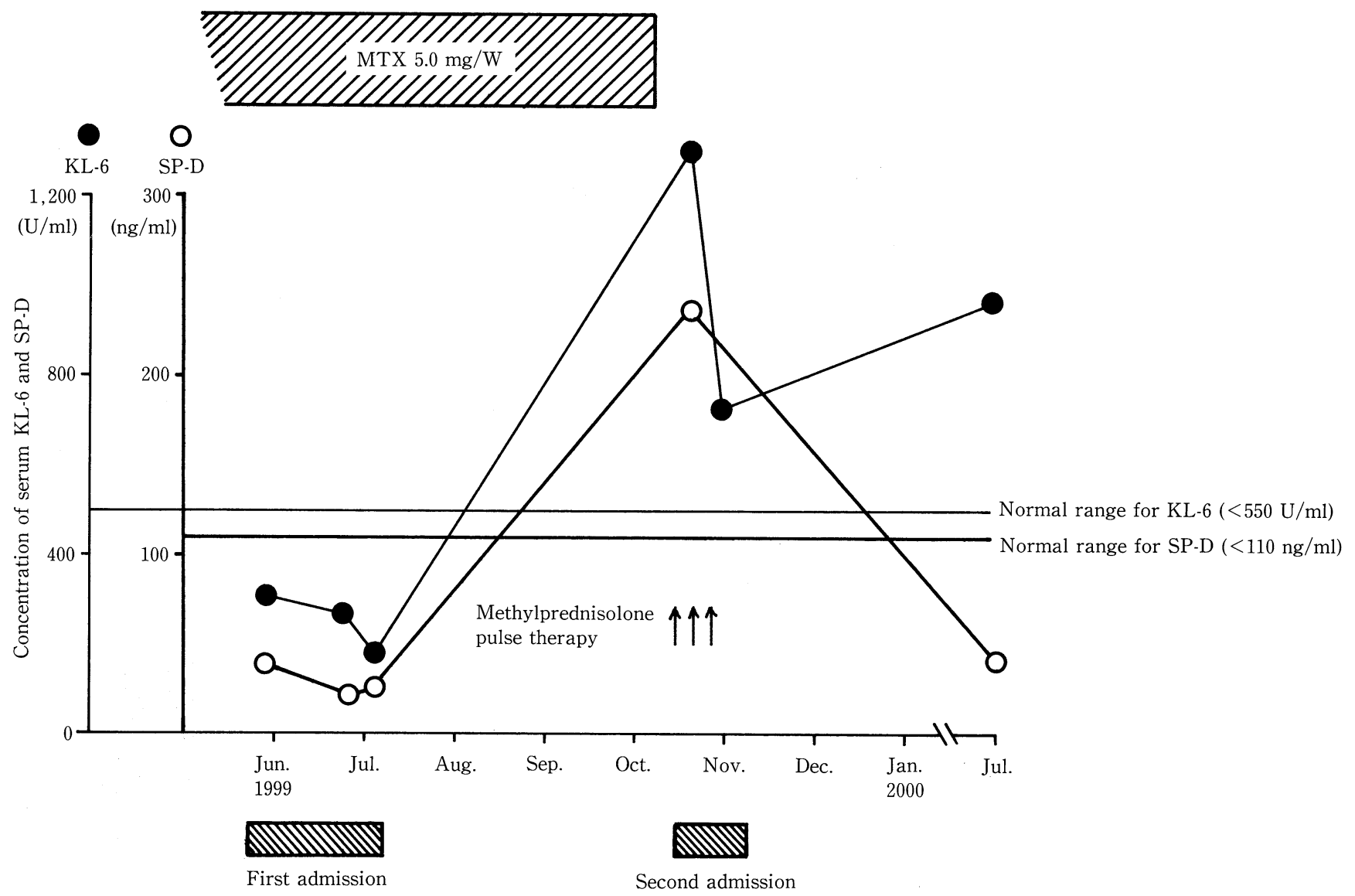

Figure 3. Clinical course of Patient 2. This patient suffered from RA since 1988 and was undergoing treatment with a $5 \mathrm{mg} / \mathrm{day}$ weekly pulse of MTX since March 1999. She was hospitalized in May 1999 to investigate malignancy of an abnormal shadow in the right middle lung field (first admission). She was hospitalized again in 1999 because of MTX pneumonitis (second admission). The concentrations of serum KL-6 and SP-D increased to 1,270 U/ml (normal: $<550$ ) and $239 \mathrm{ng} / \mathrm{ml}$ (normal: $<110$ ), respectively. Methylprednisolone pulse therapy $(1,000 \mathrm{mg} /$ day $\times 3$ days $)$ was initiated and the concentrations of serum $\mathrm{KL}-6$ and SP-D decreased to $677 \mathrm{U} / \mathrm{ml}$ and $44.0 \mathrm{ng} / \mathrm{ml}$, respectively. However, the concentration of serum KL-6 later increased again to 965 U/ml, but not that of SP-D. 

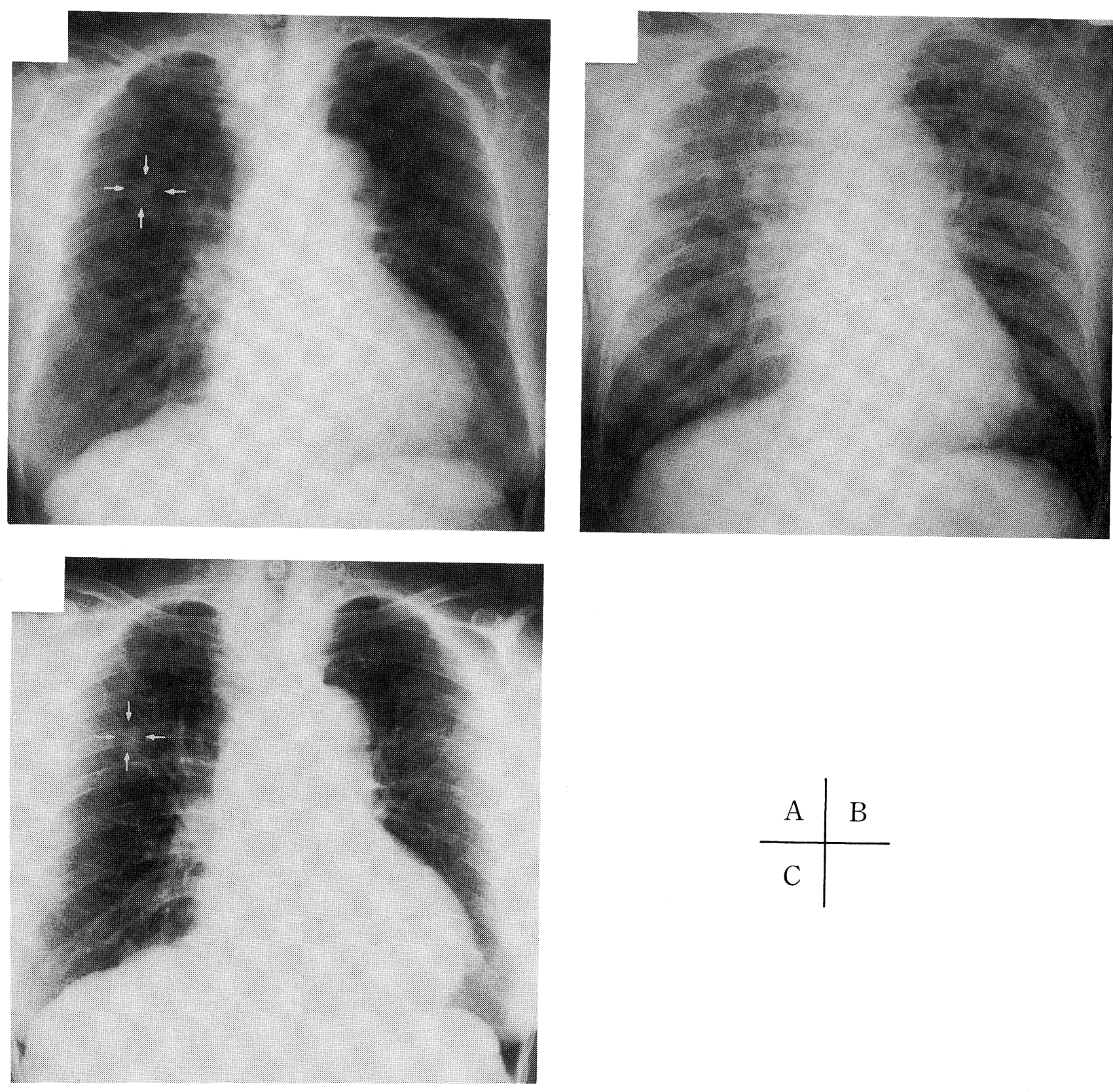

Figure 4. The roentgenograms of Patient 2. The roentgenogram taken in May 1999 reveals an abnormal lesion in the right middle lung field as indicated by arrows in (A). The roentgenogram taken in October 1999 reveals widespread interstitial pneumonia in both lung fields as shown in (B). The roentgenogram taken recently reveals the apparent accumulation of the vascular marking, although there is no change in the size of the pulmonary tumor as shown in (C).

She was hospitalized again in October 1999, to investigate the cause of fever, dry cough, shortness of breath and nausea which started 3 days prior to the second admission. The representative laboratory data on admission were as follows: serum KL-6, 1,270 U/ml (normal: <500); serum SP-D, $239 \mathrm{ng} / \mathrm{ml}$ (normal: <110); CRP, $6.6 \mathrm{mg} / \mathrm{dl}$; LDH, $506 \mathrm{IU} / \mathrm{l}$ (normal: 250 410); $\mathrm{BUN}, 31 \mathrm{mg} / \mathrm{ml}$; creatinine, $2.3 \mathrm{mg} / \mathrm{dl} ; \mathrm{PaO}_{2}, 30.6 \mathrm{mmHg}$; and $\mathrm{PaCO}_{2}, 23.6 \mathrm{mmHg}$. The roentgenogram revealed pneumonitis in both middle lung fields as shown in Fig. 4B. The cumulative amount of MTX she received was $140 \mathrm{mg}$.

The patient was diagnosed as having MTX pneumonitis under the revised diagnostic criteria for adverse pulmonary events associated with MTX treatment of RA (13). Methylprednisolone pulse therapy $(1,000 \mathrm{mg} / \mathrm{day} \times 3$ days $)$ was initi- 
ated based on the diagnosis of MTX pneumonitis. The concentrations of serum KL-6 and SP-D were 1,270 U/ml and $239 \mathrm{ng} /$ $\mathrm{ml}$, respectively, on admission and decreased to $677 \mathrm{U} / \mathrm{ml}$ and $44.0 \mathrm{ng} / \mathrm{ml}$, respectively, along with the improvement of dyspnea and roentgenographic findings. However, the serum KL-6 concentration, but not that of SP-D, later increased again to $965 \mathrm{U} / \mathrm{ml}$. The roentgenogram taken recently revealed the apparent accumulation of the vascular marking, although there was no change in the size of the pulmonary tumor as shown in Fig. 4C. We again recommended to her that she undergo an operation, but to date she has refused an operation.

\section{Discussion}

Both Patients 1and 2 exhibited strong risk factors for MTX pneumonitis proposed by Alarcon et al (3) such as old age ( $\geq 60$ years old), previous use of disease-modifying antirheumatic drugs, and hypoalbuminemia $(<3.9 \mathrm{~g} / \mathrm{dl})$. Moreover, Patient 1 had a preexisting IP and Patient 2 had diabetes mellitus as additional risk factors.

It is necessary to evaluate the activity of preexisting IP in prescribing MTX to RA patients. To evaluate and monitor the activities of the IP, chest roentgenogram, CT scan, lung function testing, gallium- 67 lung scan, and bronchoalveolar lavage have been clinically used (14). However, there are problems regarding the sensitivity, effort-dependability, and ease of repetition of these examinations.

KL-6 is a glycoprotein antigen expressed mainly on type II pneumocytes and respiratory bronchiolar epithelial cells (7). The serum concentration of KL- 6 was elevated in the majority of patients with interstitial pulmonary disease, including idiopathic IP, IP associated with collagen vascular diseases and hypersensitivity pneumonitis (10). The concentrations of serum KL-6 are significantly higher in patients with active lung disease than in those with inactive lung disease. For example, elevation of serum KL- 6 concentration was detected in $88.9 \%$ of RA patients with active IP but in only $0.6 \%$ of those with inactive IP (15). It was demonstrated that concentrations of serum KL-6 may be dependent on alveolar-capillary permeability (16); moreover, proinflammatory cytokines such as tumor necrosis factor and interferon- $\gamma$ can augment the expression of KL-6 on type II pneumocytes (17). Corticosteroid inhibits proinflammatory cytokine production and secondarily reduces KL-6 production. Corticosteroid further decreases alveolar-capillary permeability caused by inflammation, resulting in a decrease in the leakage of KL- 6 from the lung to the blood stream.

Alveolar surfactants, classified into surfactant proteins A (SP-A), SP-B, SP-C and SP-D, synthesized and secreted into the fluid layer by alveolar type II pneumocytes cover the alveolar epithelium. The concentration of serum SP-D is a valuable marker to detect active IP since it is elevated in accordance with proliferation of type II pneumocytes and destruction of the basement membrane of alveolar structures in patients with IP (18).

Both serum KL-6 and SP-D concentrations were within normal limits before the onset of pulmonary tuberculosis in Patient 1 , even though he had a preexisting IP. These data and his roentgenograms sequentially taken previously (data not shown) suggest that his IP was inactive. The serum KL-6 concentration, but not the serum SP-D concentration, increased from $273 \mathrm{U} / \mathrm{ml}$ in August 1997 to $576 \mathrm{U} / \mathrm{ml}$ in June 1998 when he suffered from pulmonary tuberculosis. The increase in the titer of KL- 6 can be explained by the presence of active and widespread lesions of pulmonary tuberculosis; Inoue et al reported that serum KL-6 can be a useful marker for determining the degree and extent of pulmonary tuberculosis (19). In contrast, the serum SP-D concentration remained within the normal range.

We predicted that serum KL-6 and SP-D concentrations would increase in the case of MTX pneumonitis since representative histopathologic changes in cases with this condition are the presence of active injury in the form of type II pneumocyte hyperplasia and fibroblastic proliferation (13). As expected, both serum KL-6 and SP-D concentrations increased along with the severity of MTX pneumonitis in Patients 1 and 2 ; however, the magnitude of the decrease in the serum KL-6 concentration with the improvement of symptoms was smaller than that in the serum SP-D concentration as seen in Patient 1. As described above, the MTX pneumonitis in Patient 1 was not completely resolved as determined by roentgenography at the end of March; accordingly, the serum KL-6 concentration was still high $(747 \mathrm{U} / \mathrm{ml})$ although he had no respiratory complaints.

The reason for the elevation of serum KL-6 concentration recently seen in Patient 2 could be explained by the presence of the pulmonary lesion which is most likely a pulmonary adenocarcinoma, since an elevated serum KL-6 concentration is frequently observed in patients with pulmonary adenocarcinoma [52\% (17/33)] (11).

Both KL-6 and SP-D are secreted by type II pneumocytes, but their biochemical properties differ. KL- 6 has biochemical properties functioning as a chemotactic factor for most fibroblasts, and increased KL-6 concentrations in the epithelial lining fluid in small airways may cause intra-alveolar fibrosis in pulmonary diseases (20). In contrast, SP-D interacts with type II pneumocytes as well as with macrophages, resulting in enhancement of phagocytosis of a wide spectrum of microorganisms (21). From these observations, it can be speculated that serum concentrations of KL-6 and SP-D may be implicated in the pulmonary fibrosis and in the activation of macrophages, respectively.

Only one study comparing the significance of serum concentrations of KL-6 and SP-D was published. It demonstrated the superiority of serum KL-6 to serum SP-D in terms of sensitivity for detection of IP and, conversely, serum SP-D may be more specific to IP than serum KL-6 (22). Either concentration, serum KL-6 or SP-D, can be used to evaluate the disease activity of IP. However, we found that serum KL-6, but not serum SP-D concentration, was elevated in cases of pulmonary tuberculosis and pulmonary adenocarcinoma, confirming previous reports $(11,19)$ and arguing for the specificity of SP- 


\section{KL-6/SP-D in MTX Pneumonitis}

D to IP. The magnitude of the decrease in serum KL-6 concentration in response to the treatment for MTX pneumonitis was small compared with that of serum SP-D.

This study involved only two patients. However, these markers appear quite useful based on this study and previous studies $(10,15)$ considering that the MTX penumonitis is sometimes fatal, even though MTX treatment is already standardized in RA therapy. Moreover, a recent prospective study reported that the occurrence of MTX pneumonitis could not be predicted by periodic pulmonary function testing (23). Therefore, we venture to draw the following conclusion on the significance of monitoring serum KL-6 and SP-D concentrations: Monitoring of serum concentrations of KL-6 and SP-D is valuable in detecting the occurrence of MTX pneumonitis, even in RA patients with preexisting IP, and in detecting the therapeutic response of MTX pneumonitis.

Parenchymal cell damage, such as that of type II pneumocytes, precedes fibrotic changes in the interstitium of patients with MTX pneumonitis; therefore, serum KL-6 and SP-D concentrations could be elevated prior to detection by pulmonary function testing, roentgenography and CT. Further prospective studies are required to determine whether or not these serum markers are useful in predicting the onset of MTX pneumonitis.

Acknowledgements: We are indebted to Ms. K. Omata for preparing this manuscript and Ms. C. Abe and Ms. Y. Yamada for preparing the pictures presented in this manuscript.

This work was supported in part by a grant from the Foundation for Research Committee for the treatment of early rheumatoid arthritis, supported by the Japanese Ministry of Health and Welfare.

\section{References}

1) Searles G, McKendry RJ. Methotrexate pneumonitis in rheumatoid arthritis: potential risk factors. Four case reports and a review of the literature. J Rheumatol 14: 1164-1171, 1987.

2) Golden MR, Katz RS, Balk RA, Golden HE. The relationship of preexisting lung disease to the development of methotrexate pneumonitis in patients with rheumatoid arthritis. J Rheumatol 22: 1043-1047, 1995.

3) Alarcon GS, Kremer JM, Macaluso M, et al. Risk factors for methotrexate-induced lung injury in patients with rheumatoid arthritis. A multicenter, case-control study. Methotrexate-Lung Study Group. Ann Intern Med 127: 356-364, 1997.

4) Carroll GJ, Thomas R, Phatouros CC, et al. Incidence, prevalence and possible risk factors for pneumonitis in patients with rheumatoid arthritis receiving methotrexate. J Rheumatol 21: 51-54, 1994.

5) Popper MS, Bogdonoff ML, Hughes RL. Interstitial rheumatoid lung disease. A reassessment and review of the literature. Chest 62: 243-250, 1972.

6) Frank ST, Weg JG, Harkleroad LE, Fitch RF. Pulmonary dysfunction in rheumatoid disease.Chest 63: 27-34, 1973.

7) Kohno N, Kyoizumi S, Awaya Y, Fukuhara H, Yamakido M, Akiyama M. New serum indicator of interstitial pneumonitis activity. Sialylated carbohydrate antigen KL-6. Chest 96: 68-73, 1989.

8) Kohno N, Yokoyama A, Hirasawa Y, et al. Comparative studies of circulating KL-6, type III procollagen N-terminal peptide and type IV collagen $7 \mathrm{~S}$ in patients with interstitial pneumonitis and alveolar pneumonia. Respir Med 91: 558-561, 1997.

9) Honda Y, Kuroki Y, Matsuura E, et al. Pulmonary surfactant protein D in sera and bronchoalveolar lavage fluids. Am J Respir Crit Care Med 152: 1860-1866, 1995.

10) Nakajima $H$, Harigai $M$, Hara $M$, et al. KL-6 as a novel serum marker for interstitial pneumonia associated with collagen diseases. J Rheumatol 27: 1164-1170, 2000.

11) Kohno N, Akiyama M, Kyoizumi S, Hakoda M, Kobuke K, Yamakido M. Detection of soluble tumor-associated antigens in sera and effusions using novel monoclonal antibodies, KL-3 and KL-6, against lung adenocarcinoma. Jpn J Clin Oncol 18: 203-216, 1988.

12) Inoue $T$, Matsuura $E$, Nagata $A$, et al. Enzyme-linked immunosorbent assay for human pulmonary surfactant protein D. J Immunol Methods 173: 157-164, 1994.

13) Kremer JM, Alarcon GS, Weinblatt ME, et al. Clinical, laboratory, radiographic, and histopathologic features of methotrexate-associated lung injury in patients with rheumatoid arthritis: a multicenter study with literature review. Arthritis Rheum 40: 1829-1837, 1997.

14) King TE Jr. Idiopathic Pulmonary Fibrosis. in: Interstitial Lung Disease, 2nd ed. Schwarz MI, King TE Jr, Eds. Mosby Year Book, St. Louis, 1993: $367-404$.

15) Oyama T, Kohno N, Yokoyama A, et al. Detection of interstitial pneumonitis in patients with rheumatoid arthritis by measuring circulating levels of KL-6, a human MUC1 mucin. Lung 175: 379-385, 1997.

16) Inoue Y, Barker E, Daniloff E, Kohno N, Hiwada K, Newman LS. Pulmonary epithelial cell injury and alveolar-capillary permeability in berylliosis. Am J Respir Crit Care Med 156: 109-115, 1997.

17) Novotny-Smith CL, Zorbas MA, McIsaac AM, et al. Down-modulation of epidermal growth factor receptor accompanies TNF-induced differentiation of the DiFi human adenocarcinoma cell line toward a goblet-like phenotype. J Cell Physiol 157: 253-262, 1993.

18) Kuroki Y, Takahashi H, Chiba H, Akino T. Surfactant proteins A and D: disease markers. Biochim Biophys Acta 1408: 334-345, 1998.

19) Inoue $Y$, Nishimura $K$, Shiode $M$, et al. Evaluation of serum KL-6 levels in patients with pulmonary tuberculosis. Tuber Lung Dis 76: 230-233, 1995.

20) Hirasawa Y, Kohno N, Yokoyama A, Inoue Y, Abe M, Hiwada K. KL-6, a human MUC1 mucin, is chemotactic for human fibroblasts. Am J Respir Cell Mol Biol 17: 501-507, 1997.

21) Sano H, Chiba H, Iwaki D, Sohma H, Voelker DR, Kuroki Y. Surfactant proteins $\mathrm{A}$ and D bind CD14 by different mechanisms. J Biol Chem 275: 22442-22451, 2000.

22) Sugimoto H, Okada E, Hashimoto N, et al. The clinical study on KL-6 and SP-D in sera of patients with various pulmonary diseases. Rinsho Byori 48: 554-560, 2000.

23) Cottin V, Tebib J, Massonnet B, Souquet PJ, Bernard JP. Pulmonary function in patients receiving long-term low-dose methotrexate. Chest 109: 933-938, 1996. 